\title{
Pattern of Acne vulgaris in a Tertiary Care Hospital of Bangladesh
}

\author{
Quader $\mathrm{MR}^{1}$, Rahaman $\mathrm{MM}^{2}$, Kumar $\mathrm{SB}^{3}$, Siddique $\mathrm{MRU}^{4}$, Wahab $\mathrm{MA}^{5}$
}

\begin{abstract}
A cross-sectional study was carried out for a period of six months in the outpatient Department of Dermatology and Venereology, Bangabandhu Sheikh Mujib Medical University (BSMMU), Dhaka, Bangladesh. Ninty three patients having acne vulgaris were selected. The study showed that the mean age of the cases was 20.7 with standard deviation 5.4 years. Highest percentage of patients was unmarried among the cases (79.6\%) and proportion of higher secondary education $(63.4 \%)$ was found to be high among the cases. The study showed that proportion of student $(75.3 \%)$ and housewife $(12.9 \%)$ were found to be high among the cases. All the patients had presented with comedones (blackheads and whiteheads). All the patients had acne in the face and it was found that $78.5 \% \%$ had papules, $17.2 \%$ had pustules $\& 4.3 \%$ had nodules. $90.3 \%$ patients presented with multiple lesions. $95.7 \%$ lesions are on check.Considering the pattern of treatment received, $28 \%$ of the patients mentioned that they used topical steroid, $19.6 \%$ had received retinoids and $28 \%$ had received antibiotics. To get an overall impression of the country regarding acne vulgaris, more integrated study is needed. This was a study on a limited number of cases. Future studies must include economical support, then large sample size could be ensured and study finding would be more reliable. There is a great need of epidemiological studies also, with sufficient follow-up, systematic reviews and meta-analyses on this issue.
\end{abstract}

Key words: Acne vulgaris, pattern of acne.

CBMJ 2016 July: Vol. 05 No. 02 P: 33-38

\section{Introduction}

Acne vulgaris is the most common disease involving the pilosebaceous unit, affecting in particular the face, back and chest although occasionally it may be wide spread ${ }^{18}$. It is a chronic inflammatory disease of the pilosebaceous follicles characterized by comedones, papules, pustules, cysts, nodules and often scars ${ }^{19}$. The condition usually starts in adolescence and resolves by the midtwenties. However, in $7-17 \%$ of individuals clinical acne persists beyond the age of 25 years with physiological acne in females having a prevalence of $24 \%$. A genetic influence is confirmed by the very high concordance between monogygotic twins, in whom the sebum excretion rate (SER) is virtually identical. Patients with persistent acne have a strong family history of persistent acne, in contrast to patients with adolescent acne ${ }^{20}$. Active sebaceous glands are a prerequisite for the development of acne. Acne patients, male and female, excrete on average, more sebum than normal subjects and the level of secretion correlates reasonably well with the severity of the acne. One of the components of sebum, triglycerides may play a role in acne pathogenesis. Triglycerides are broken down into free fatty acids by $\mathrm{P}$. acnes, normal flora of pilosebaceous unit. These free fatty acids (FFA) promote further bacterial clumping and

\footnotetext{
1. Dr. Md. Rezaul Quader

Senior Consultant

BSMMU,Dhaka

2. DrMd Mahabubur Rahaman

Associate Professor(Ex) \& Senior Consultant

Aurora Skin \& Aesthetics, Dhaka

3. Dr Saha Bijoy Kumar

Assistant Professor

Comilla Medical College

4. Dr Md Rahmat Ullah Siddique

Research Assistant

BSMMU, Dhaka

5. Professor Md. Abdul Wahab Professor, BSMMU

Dhaka

"Address of correspondence

Phone : 01819181083

Email: rezaulq@gmail.com
} 
colonization of $P$. acnes, incite inflammation and may be comedogenic ${ }^{21}$.Sebaceous activity is predominantly dependent on androgenic hormones of gonadal or adrenal origin. An important feature in the aetiology of acne is the presence of ductal hypercornification ${ }^{3}$.Several proposed factors in keratinocyte hyperproliferation include: androgen stimulation, decreased linoleic acid and increased IL- 10 activity ${ }^{21}$. The three major organisms isolated from the surface of the skin and pilosebaceous ducts of patients with acne are P. acnes, Staphylococcus epidermidis and Malassezia furfur ${ }^{20}$. P. acnes plays an active role in the process of inflammation ${ }^{21}$.P. acnes is non motile but easily colonizes the duct.

In early inflammation proinflammatory mediators move through the duct wall into the dermis. In papules, helper $T$ cells are the first inflammatory cells to be seen ${ }^{20}$. As the retained cells block the follicular opening, the lower portion of the follicle is dilated ${ }^{2}$.Eventually this distension causes follicular wall rupture ${ }^{21}$.The combination of keratin, sebum and microorganisms particularly P. acnes leads to release of proinflammatory mediators ${ }^{19}$.The predominant cell type within 24 hours of comedo rupture is the lymphocyte. CD4+ lymphocytes are found around the pilosebaceous unit whereas CD8+ cells are found perivascularly. One to two days after comedo rupture, the neurophil becomes the predominant cell type surrounding the burst microcomedo ${ }^{21}$.Nodules more frequently occur in males and if exudative or haemorrhagic, are particularly disfiguring and messy. Scarring usually follows deep inflammatory lesions but may often happen after superficial lesions in scarprone patients. Scars may show increased collagen (hypertrophic scars and keloids) or be associated with loss of collagen (i.e. ice pick scars, depressed fibrotic scars, atrophic macules and peri-follicular elastolysis) ${ }^{20}$. Diagnosis is usually easy but acne may be confused with folliculitis, rosacea or perioral dermatitis. These do not have comedone. Acne can also be seen in association with different endocrinologic abnormalities, such as polycystic ovarian syndrome including hyperandrogenism, insulin resistance, canthosisnigricans, hirsutism, deepening of voice, irregular menses etc.Various acne treatments targets different elements in acne pathogenesis ${ }^{21}$. The management of acne starts with education. This is largely determined by the severity and extent of the disease but should be tempered by patient choice and cost. Patient with mild acne usually receive topical therapy alone; patients with moderate acne receive oral and topical therapies; patients with severe acne should immediately receive oral isotretinoin unless contraindicated.

\section{Methods}

It was a cross-sectional study. The study was carried out for a period of six months fromjune 2016 to November, 2016, in the outpatient Department of Dermatology and Venereology, Bangabandhu Sheikh Mujib Medical University (BSMMU), Dhaka, Bangladesh. Patients having acne vulgaris were selected as study population. Purposive type of non-probability sampling technique was followed. Data were recorded on pre designed data collection sheet. Within the period of data collection, patients were assigned purposively considering exclusion and inclusion criteria of patient selection.

\section{Inclusion criteria for case:}

Patients having clinically diagnosed acne vulgaris. (Seborrhea i.e. greasy skin, comedones, papules, pustules, nodules and scarring, in some cases, predominantly on the face and to a lesser extent on the back and chest.)

i. Female patients of age 2 to 45 years.

ii. Patients willing to participate in this study.

Exclusion criteria for case:

i. Pregnant women and lactating mothers.

ii. Patients treated with oral contraceptive pill, antiandrogen, systemic antibiotics and oral retinoids within 3 months prior to the study.

\section{Study procedure:}

Clinically suspected cases of acne vulgaris 
attending in the outpatient Department of Dermatology and Venereology, BSMMU, Dhaka were seen. All patients participating in the study gave informed consent. According to a structured questionnaire their particulars and history were taken. Patients for the study were selected on the basis of history, clinical examination and inclusion and exclusion criterias. Acne vulgaris was diagnosed by seborrhea (greasy skin), comedones, papules, pustules, nodules and scarring, in some cases, predominantly on the face and to a lesser extent on the back and chest.

Acne vulgaris was graded using a simple grading system taking into account the predominant lesion to grade acne, which classifies acne vulgaris into four grades.

Grade 1:

Comedones, occasional papules

Grade 2:

Papules, comedones, few pustules

Grade 3:

Predominant pustules, nodules, abscesses

Grade 4:

Mainly cysts, abscesses, widespread scarring

Data were entered into a compatible personal computer using statistical package for social sciences (SPSS) version 10. Statistical analysis was performed with Chi-square test for qualitative variables, and t-test for quantitative variables. A p-value of less than 0.05 was considered as the statistical level of significance.

\section{Results}

The study was carried out for a period of six months from in the outpatient department of Dermatology and Venereology, Bangabandhu Sheikh Mujib Medical University (BSMMU), Dhaka, Bangladesh. Patients having acne vulgaris were selected as study population.

Table- I showed that the mean age of the cases was 20.7 with standard deviation 5.4 years \%). It was showed that male patients are $52.7 \%$ \& female patients are $47.3 \%$ and highest percentage of patients was unmarried among the cases $(79.6 \%)$. Table- I also showed that $96.8 \%$ patients are muslim and proportion of higher secondary education $(63.4 \%)$ were found to be high among the cases and the proportion of student $(75.3 \%)$ and housewife (12.9\%) were found to be high among the cases. $63.4 \%$ patients have no family history \& $90.9 \%$ patients have regular menstrual history. Among all the patients ,28\% have history of taking topical steroid, $28 \%$ used topical antibiotics.

Table-2 showed all the patients had presented with comedones (blackheads and whiteheads) followed by $78.5 \%$ had papules and $54.8 \%$ had pustules. $90.3 \%$ patients have multiple lesions .Considering the site of lesion, all the patients had acne in the face \& common site of involvement is check $(90.3 \%)$.

Considering the skin condition, $82 \%$ of the patients have oily skin.Regarding the grading,56\% patients are in grade- 2 .

Table-1: Baseline socio-demographicand other characteristics of the study population $(n=93)$

\begin{tabular}{|c|c|}
\hline Characteristics & n (\%) \\
\hline Age, years: mean ( $\pm S D$ ), Range & $20.7(5.4), 2-45$ \\
\hline Gender, male/female: $n(\%)$ & $49(52.7) / 44(47.3)$ \\
\hline $\begin{array}{l}\text { Marital status, married/unmarried: } \\
\text { n (\%) }\end{array}$ & $19(20.4) / 74(79.6)$ \\
\hline $\begin{array}{l}\text { Religion, muslim/hindu/Christian: } \\
\mathrm{n}(\%)\end{array}$ & $90(96.8) / 2(2.2) / 1(1.1)$ \\
\hline $\begin{array}{l}\text { Level of education, illiterate/primary/ } \\
\text { secondary/ higher secondary/ } \\
\text { graduate and above: } n(\%)\end{array}$ & $\begin{array}{c}5(5.4) / 14(15) / 11 \\
(11.8) / 59 \\
(63.4) / 4(4.3)\end{array}$ \\
\hline $\begin{array}{l}\text { Occupation,unemployed/student/ } \\
\text { housewife /business/service/day } \\
\text { laborer: } \mathrm{n}(\%)\end{array}$ & $\begin{array}{c}4(4.3) / 70(75.3) / \\
12(12.9) / \\
2(2.2) / 5(5.4) / 4(4.3)\end{array}$ \\
\hline $\begin{array}{l}\text { Family history, positive/negative: } \\
\mathrm{n}(\%)\end{array}$ & $34(36.6) / 59(63.4)$ \\
\hline $\begin{array}{l}\text { Menstrual history, regular/irregular: } \\
n(\%)\end{array}$ & $40(90.9) / 4(9.1)$ \\
\hline $\begin{array}{l}\text { Drug history, topical steroid/topical } \\
\text { retinoid/topical antibiotics/absent } \\
\text { n (\%) }\end{array}$ & $\begin{array}{c}26(28) / 18(19.6) / \\
26(28) / 23 \\
(24.7) \\
\end{array}$ \\
\hline
\end{tabular}

Table-2: Characteristics of the lesions of the study population

\begin{tabular}{|c|c|c|}
\hline Characteristics & $\begin{array}{c}\text { Number of } \\
\text { patients }\end{array}$ & $\begin{array}{c}\text { Percentage } \\
(\%)\end{array}$ \\
\hline Types of lesion & & \\
\hline Comedone & 93 & 100 \\
Papule & 73 & 78.5 \\
Pustule & 51 & 54.8 \\
Cyst/Scar & 4 & 4.3 \\
\hline Number of lesions & & \\
\hline Single & 9 & 9.7 \\
Multiple & 84 & 90.3 \\
\hline Site of leslons & & \\
\hline Check & 89 & 95.7 \\
Others & 4 & 4.3 \\
\hline
\end{tabular}




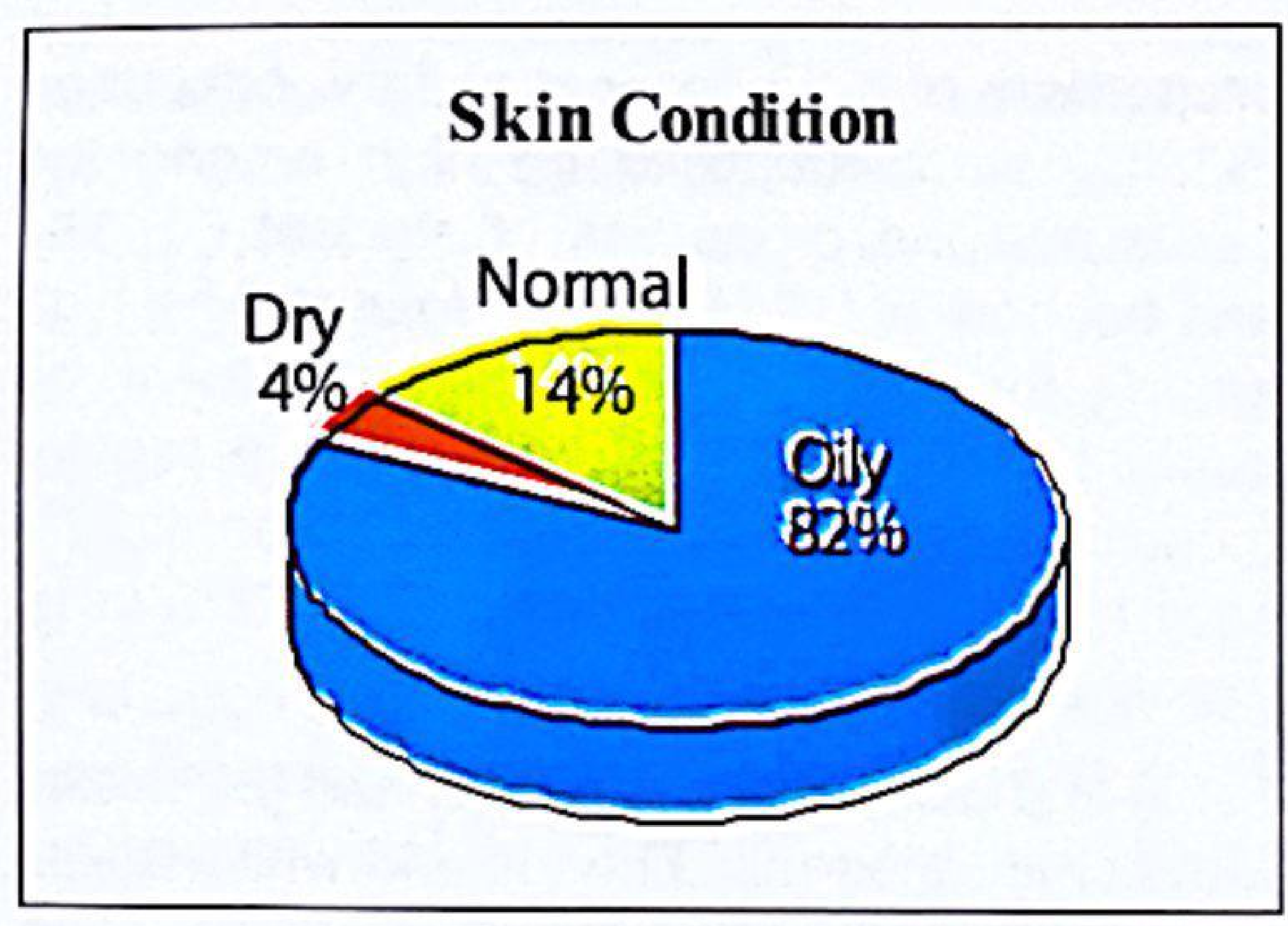

Figure-1: Skin conditions of the study population

Table-3: Acne Vulgaris-Number of grading of patients

\begin{tabular}{|c|c|c|}
\hline Characteristics & $\begin{array}{c}\text { Number of } \\
\text { patients }\end{array}$ & $\begin{array}{c}\text { Percentage } \\
\text { (\%) }\end{array}$ \\
\hline Grading & & \\
\hline Grade-1 & 13 & 17 \\
Grade-2 & 44 & 56 \\
Grade-3 & 29 & 22 \\
Grade-4 & 7 & 5 \\
Total & 93 & 100 \\
\hline
\end{tabular}

Grading of Acne Vulgaris
Grade-1 : Comedone only
Grade-4 : Grade-3+Cyst/Scar

Figure-2: Grading of acne vulgaris

\section{Discussion}

This study was carried out in the Department of Dermatology and Venereology, Bangabandhu Sheikh Mujib Medical University, Dhaka. Age of the patients in this study ranged from 2 to 45 years.

Acne is one of the most common skin disorders worldwide and occurs primarily at puberty with a prevalence of almost $95 \%$.It is generally limited to skin areas rich in sebaceous glandsSpecially on face ${ }^{1}$.Noninflammatory lesions of acne include white (closed) and black (open) comedones ${ }^{1,2}$. The inflammatory lesions vary from small papules to pustules to large, tender, fluctuant nodules. Some of the large nodules have previously been called cysts, and the term nodulocystic has been used to describe severe cases of inflammatory acne ${ }^{2}$.

In the present study, inflammatory acne was the predominant type. It was seen in slightly more than three quarters of acne patients. These findings are in line with those noted by Gouldenet $\mathrm{al}^{4}$ in spite of the difference in the mean age of the two studies.

All acne patients in this study had facial lesions. This finding is nearly the same as that reported by Cunliffe and Williams ${ }^{5}$.In slightly more than three quarters of the patients, the face alone was involved. Both facial and truncal lesions were seen in approximately a quarter of the cases. These findings are in a close agreement with what was observed by Patricia and Chee-Leok ${ }^{6}$.

In this study, seborrhea (greasy skin) was the most common associated condition occurring in almost $82 \%$ of cases. Several studies have indicated that seborrhea is a frequent finding in acne ${ }^{5,7}$. Furthermore, acne patients excrete more sebum than normal subjects, and the level of secretion correlates reasonably well with the severity of the disease ${ }^{8}$.

Dandruff was reported in $4 \%$ of the acne patients. However, like many dermatological symptoms, though not easy to assess clinically, it is probably more prevalent in patients with acne ${ }^{9}$.

Premenstrual flare was found in $9.8 \%$ of female acne patients which is less than that reported in western studies, which is almost $70 \%{ }^{5,10}$.

Acne vulgaris represents one of the most common chronic skin diseases and is the commonest dermatological disorder of adolescents $^{1,5}$

The earlier onset of clinical acne in girls than boys is presumably related to their earlier puberty.

In a case control study by Slayden et al. ages of the patients ranged from 12 to 43 years. Patients with acne and controls had similar 
mean $( \pm S D)$ age $(26.5 \pm 9.3$ years vs. $29.2 \pm 4.7$ years respectively). ${ }^{11}$

In a study by Al-Ameer and Al-Akloby ${ }^{12}$ the age at presentation was $19.2 \pm 3.0$ years for males and $18.4 \pm 4.2$ years for females. Kane et $\mathrm{al}^{13}$ noted that the mean age of presentation of their patients was 25.58 years, whereas Adityan B and Thappa DM ${ }^{14}$. found in their study that the mean age of patients was 19.78 years $(S D \pm 4.94)$. The mean age of patients in our study population was 20.7 years with standard deviation 5.4 years which is almost similar to other studies mentioned.

All of our study patients presented with acne in the face. The lesions of acne vulgaris were present in the back along with face is $17.1 \%$ of the cases. Simpson and Cunliffe2004 showed that acne occurred predominantly on the face (99\% of sufferers) and to a lesser extent, occurred on the back (60\%) and chest $(15 \%) 8$ Considering the affection of face our study was consistent with that of Simpson and Cunliffe.

In our study, $40 \%$ of patients had mild acne and $55 \%$ had moderate acne \& $5 \%$ severe acne. In their case control study, Lookingbill et al. showed that mild acne was present in $44.44 \%$ of cases and moderate acne in $55.55 \%$ of cases $^{8}$ which is similar to our study.

The preadolescent acne and the beginning of adolescent acne is largely comedonal ${ }^{20}$

In our study,we graded the severity of acne vulgaris using a simple and quick system of classification using a four-grade syste ${ }^{3}$ The most common type of lesion in our group of acne patients was closed comedones. Majority of our patients were having acne grade $2(56 \%)$ followed by grade $1(17 \%)$, grade $3(22 \%)$ and grade $4(5 \%)$. In the study by Adityan $B$ and ThappaDM ${ }^{14}$,grade 1 acne vulgaris was most common and similar findings was noticed by Kane et $\mathrm{al}^{13}$; however, the lesions were mainly comedones.

Kilkennyet $\mathrm{al}^{15}$ and Cunliffeet $\mathrm{al}^{16}$ reported that comedones were the most common type of lesion.

Cibula et al. evaluated and examined the patients consecutively in an outpatient unit for acne vlugaris over the years 1998-99 were included in the study. Inclusion criteria were age over 17 years, absence of hormonal therapy during the past 6 months and absence of therapy with systemic antibiotics or isotretinion at the time of examination. Patients with severe acne were not included as most women with this severity of acne did not meet the inclusion criteria of absence of systemic therapy. Ninety women over 17 years of age with acne were enrolled into the study. The patients were divided into three groups according to acne severity. Acne was graded using the Leeds technique as minor in $43(48 \%)$ cases, mild in $27(30 \%)$ and moderate in $20(22 \%)^{17}$.

\section{Conclusion}

The study we conducted here is with a limited number of cases. We need future studies must include economical support, then large sample size could be ensured and study finding would be more reliable. Epidemiological studies are essential with sufficient follow-up, systematic reviews and meta-analysis on this issue.

\section{Reference}

1. Brown SK, Shalita AR. Acne vulgaris. Lancet. 1998;351:1871-6.

2. John SS, Diane MT. Diseases of the Sebaceous Glands. In: Fitzpatrick TB, Eisen AL, Wolff $K$, Freedberg $I M$, Austen KF, editors. Dermatology in General Medicine. 5th ed. New York: McGraw Hill; 1999. pp. 769-83.

4. Goulden V, Clark SM, Cunliffe WJ. Post-adolescent acne: a review of clinical features. $\mathrm{Br} J$ Dermatol. 1997;136:66-70.

5. Cunliffe W J, Cotterill JA. In: The Acne: clinical features, pathogenesis and treatment. Marks Ronald., editor. London: Martin Dunitz Ltd; 1989. pp. 11-75.

6. Patricia PN, Chee-Leok G. Teatment outcome of acne vulgaris with oral isotretinoin in eighty-nine patients. Int J Dermalol. 1999;38:213-6.

7. Beylot C. Seborrhea and its complications. Rev Prat. 1993:43(18):2320-7.

8. Cunliffe WJ, Simpson NB. Disorders of the Sebaceous Glands. In: Rook, Wilkinson, Ebling, editors. Textbook of Dermatology. 6th ed. Oxford: Blackwell Scientific Publications; 1998. pp. 1940-71.

9. Munro $A D$. Acne vulgaris in a public school. Trans St Johns Hosp Dermatol Soc. 1963;49:144.

10. Cunliffe, Cotterill . The Acnes: clinical features, pathogenesis and treatment. London: Lavenham Press; 1975. 
11. Slayden SM, Moran C, Sams JWM, Boots LR and Aziz R. 'Hyperandrogenemia in patients presenting with acne'. Fertility and Stenility2001; vol. 75(5): pp. 889 . 892.

12. Al-Ameer AM, Al-AklobyOM.Demographic features and seasonal variations in patients with acne vulgarisin Saudi Arabia: a hospital-based study.Int J Dermatol 2002;41(12):870-1.

13. Kane A, Niang SO, DiagneAC,etal.Epidemiological, clinical, and therapeutic features of acne in Dakar, Senegal. Int J Dermatol 2007;46(Suppl 1):36-8.

14. Adityan B, Thappa DM. Profile of acne vulgaris-a hospital-basedstudy from south India. Indian $J$ Dermatol VenereolLeprol 2009;75(3):272-8.

15. Kilkenny M, Merlin K. Plunkett A, et al. The prevalence of common skin conditions in Australian school students: 3. Acne vulgaris. BrJ Dermatol 1998;139(5) :840-5.

16. Cunliffe WJ, Holland DB, Clark SM, et al. Comedogenesis: some new aetiological, clinical and therapeutic strategies. $\mathrm{Br} J$ Dematol 2000;142(6) :1084-91.
17. Cibula $D$, Hill $M$, Vohradnikova $O$, Kuzel $D$, Fanta $M$ and Zivny J. The role of androgens in determining acne severity in adult women. British Journal of Dermatology2000; vol. 143: pp. 399- 404.

18. Cunliffe WJ. 'Acne Vulgaris: pathogenesis and treatment'. Br Med J 1980 June 14; 280(6229): pp1394-1396.

19. James WD, Berger TG and ElstonDM.Acne vulgaris'.Andrews' Diseases of the skin. Clinical dermatology. 10th ed. Philadelphia, USA: Saunders Elsevier publisher; pp. 231-239.

20. Simpson NB and Cunliffe WJ. 'Disorders of the sebaccous glands'. Rook's Text book of dermatology. 7 thed, Massachusetts, USA: Black Well Science publisher; 2004pp. 43.1-43.58.

21. Zaenglein AL, Garber EM, Thiboutot DM and Strauss JS. 'Acne vulgaris and Acneiform Eruptions'. Fitzpatrick's Dermatology in General Medicine. 7th ed, Sanfransisco, USA:, McGraw-Hill publisher; 2008.pp. 690-696. 